Week4, 8, 12, 24 and 52 by LOCF method. Also we used ROC analysis in order to determine the optimal period to achieve remission for the DAS-ESR and SDAI at Week52.

Results: The group of patients included 16 males and 82 females. The mean age was $59.5 \pm 14.7$ years old; the disease duration was $9.4 \pm 8.8$ years; the patients of receiving methotrexate (MTX) was 73 cases (74\%); the MTX dose was $11.2 \pm 3.6 \mathrm{mg} /$ week and b-DMARD naïve patients was 57 cases $(61 \%)$. Clinical findings related to RA were as follows: mean tender joint count, $5.2 \pm 4.7$; swollen joint count, 5.0 \pm 4.0 ; patient's and physician's global assessment of disease activity, $48.9 \pm 27.4$ and $42.3 \pm 23.2 \mathrm{~mm}$; CRP, $1.9 \pm 2.2 \mathrm{mg} / \mathrm{dL}$; ESR, $47.4 \pm 34.0$ $\mathrm{mm} / \mathrm{h}$; MMP3, $233 \pm 186 \mathrm{ng} / \mathrm{ml}$; the rate of rheumatoid factor positive patients was $78 \%$; DAS28 (ESR), 4.84 \pm 1.36 ; and SDAI, 21.2 \pm 11.3 . The mean DAS-ESR improved to $3.54 \pm 1.35,3.31 \pm 1.46,3.37 \pm 1.47$ and $3.31 \pm 1.43$ at Week $4,12,24$ and $52(p<0.001, p<0.001, p<0.001, p<0.001)$ and the mean SDAl improved to $11.4 \pm 9.0,9.7 \pm 9.0,9.8 \pm 9.1$ and $9.4 \pm 9.1$ at Week $4,12,24$ and $52(p<0.001$, $\mathrm{p}<0.001, \mathrm{p}<0.001, \mathrm{p}<0.001$ ) significantly (Fig.1). At Week 4, 12, 24 and 52 the rate of patients who achieved remission were each $28.8,37.2,32.9,33.7 \%$ and $11.7,29.3,30.5,28.8 \%$ in DAS-ESR and SDAl criteria (Fig.2). Also at Week $4,12,24$ and 52 the rate of patients who achieved low disease activity (LDA) were each $46.6,53.2,51.2,55.8 \%$ and $58.8,64.1,65.9,71.3 \%$ in DAS-ESR and SDAI criteria. Areas under the receiver operating characteristic curves for the DAS28-ESR and SDAI at each time point for remision achievement at 52 weeks were each 0.578 and 0.702 at baseline, 0.755 and 0.822 at week4, 0.821 (cut-off index 2.73 , odds ratio 16.7 , sensitivity 0.75 , specificity, 0.85 ) and 0.856 (cut-off index 5.30 , odds ratio 29.6 , sensitivity 0.86 , specificity, 0.82 ) at week 8 , and 0.820 and 0.809 at week 12
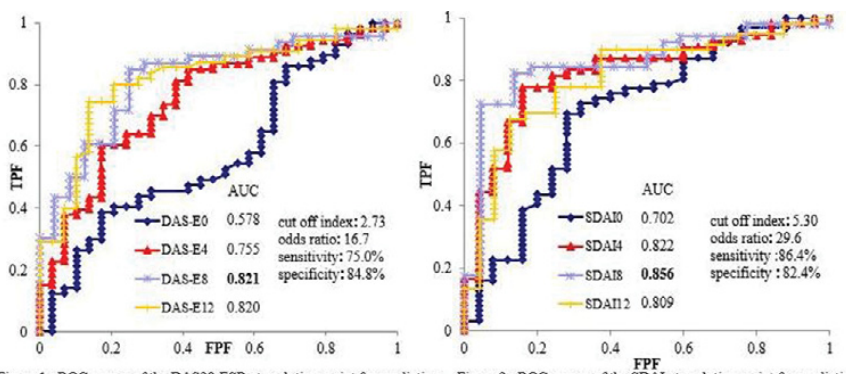

Figure 1: ROC curves of the DAS2s-ESR at each time point for predicting Figure $2:$ ROC curves of the SDA AI at each time point for predicting

Conclusions: The new TNF-antagonist therapy of CZP was effective early and rapidly in patients with active Japanese RA. This study suggested that eight weeks is an adequate optimal period to judge whether the achieved remission or not at Week 52

Disclosure of Interest: Y. Kanayama: None declared, A. Kaneko Speakers bureau: Mitsubishi Tanabe Pharma, Takeda Pharma, Eisai Pharma, Chugai Pharma, Abbott, Bristol-Myers Squibb, UCB, Janssen, and Pfizer, N. Takahashi Speakers bureau: Abbvie Japan Co. Ltd, Eisai Co. Ltd, UCB Japan Co. Ltd, MitsubishiTanabe Pharma Corporation, Takeda Pharmaceutical Company Ltd, Pfizer Co. Ltd, Chugai Pharmaceutical Co. Ltd, Janssen Pharmaceutical K.K., and, T. Kato: None declared, M. Hayashi: None declared, Y. Hattori: None declared, N. Asai: None declared, N. Ishiguro Grant/research support from: Daiichi Sankyo, Takeda Pharmaceutical, Hisamitsu Pharmaceutical, Otsuka Pharmaceutical, Taisho Toyama Pharmaceutical, Kaken Pharmaceutical, Eisai, Janssen Pharmaceutical, Bristol- Myers Squibb, AbbVie, Chugai Pharmaceutical, Mitsubishi Tanabe Pharmaceutical, Astellas Pharma, and Pfizer Japan, Speakers bureau: Daiichi Sankyo, Takeda Pharmaceutical, Hisamitsu Pharmaceutical, Otsuka Pharmaceutical, Taisho Toyama Pharmaceutical, Kaken Pharmaceutical, Eisai, Janssen Pharmaceutical, Bristol-Myers Squibb, AbbVie, Chugai, T. Kojima Speakers bureau: Mitsubishi Tanabe Pharma, Takeda Pharma, Eisai Pharma, AbbVie, Bristol-Myers Squibb, and Pfizer, Janssenn Pharmaceutical Companies, Astellas Pharma and Chugai Pharma

DOI: 10.1136/annrheumdis-2017-eular.4653

\section{SAT0175 A DESCRIPTIVE ANALYSIS OF REAL-WORLD TREATMENT PATTERNS IN A TURKISH RHEUMATOLOGY POPULATION THAT CONTINUED INNOVATOR INFLIXIMAB (REMICADE) THERAPY OR SWITCHED TO BIOSIMILAR INFLIXIMAB}

Y. Yazici ${ }^{1}$, L. Xie ${ }^{2}$, A. Ogbomo ${ }^{2}$, D. Parenti ${ }^{3}$, K. Goyal ${ }^{3}$, A. Teeple ${ }^{3}$, L. Ellis ${ }^{3}$ I. Simsek ${ }^{4}{ }^{1}$ New York University Hospital for Joint Diseases, New York; ${ }^{2}$ STATinMED Research Inc, Ann Arbor; ${ }^{3}$ Janssen Scientific Affairs, LLC, Horsham, United States; ${ }^{4}$ Guven Hospital, Ankara, Turkey

Objectives: This study examined treatment patterns in a rheumatology patient (pt) population initially prescribed innovator infliximab (IFX) that either switched to biosimilar infliximab (CT-P13) or continued on IFX following availability of CT-P13 in the Turkish healthcare system.

Methods: Adult pts with $\geq 1$ diagnosis code (ICD-10-CM M05.X; M06.X) for rheumatoid arthritis (RA) and a prescription for IFX were identified in a national Turkish health care database during the study period (01DEC2010-01DEC2015). Eligible pts were those who continued on IFX (Continuers cohort; CC) or switched from IFX to CT-P13 (Switchers cohort; SC) during the identification period; had continuous medical/pharmacy benefit enrollment $\geq 12$ months before and $\geq 6$ months after the index date (date of switch for SC and a random IFX prescription date for (C); had a prescription claim for IFX within 16 weeks of the index date during the baseline period. Demographics, concomitant disease, medications, and treatment patterns (dose, refill interval, discontinuation, and switch) were summarized. A confirmed discontinuation was defined as a switch to another biologic medication or the absence of an index biologic claim for $\geq 120$ days without censoring. Patient weight was unavailable in the dataset.

Results: Key results are shown in the Table. A total of 3018 pts met study criteria. The majority $(95 \%$; $n=2870$; CC) continued on IFX and had a mean age of 44 years; $46 \%$ were female and mean follow up of 12 months. A total of 148 pts (5\%) switched to CT-P13 (SC) and had mean age of 44 years; $51 \%$ female and mean follow up of 9 months. Approximately $40 \%$ of pts in each cohort had a concomitant diagnosis for ankylosing spondylitis (AS; Table). Other concomitant diseases and medications appeared balanced between cohorts. In the CC, pts had an average of 4.7 infusions at a mean dose of 4.4 vials approximately every 10 weeks. In the SC, pts had an average of 2.6 infusions at a mean dose of 3.6 vials approximately every 10 weeks. Therapy discontinuation occurred in $38 \%$ in the CC; average time to any discontinuation or censoring of IFX was 256 days (Table). In the SC, CT-P13 discontinuation was observed in $82 \%$; average time to any discontinuation or censoring of CT-P13 was 124 days; $74 \%$ of SC switched to another biologic with $94 \%$ of these returning to IFX.

\begin{tabular}{|c|c|c|c|c|}
\hline & \multicolumn{2}{|c|}{$\begin{array}{l}\text { Switchers Cohort } \\
(\mathrm{N}=148)\end{array}$} & \multicolumn{2}{|c|}{$\begin{array}{l}\text { Continuers Cohort } \\
(N=2870)\end{array}$} \\
\hline & N/Mean & $\% / S D$ & N/Mean & $\% / S D$ \\
\hline Age (Mean) (years) & 44 & 13 & 44 & 12 \\
\hline \multicolumn{5}{|l|}{ Gender } \\
\hline Female & 75 & $51 \%$ & 1,332 & $46 \%$ \\
\hline Average Length of Follow up Period (in Months) & 9 & 2 & 12 & 3 \\
\hline \multicolumn{5}{|l|}{ Concomitant Disease During Baseline Period } \\
\hline Ankylosing Spondylitis & 73 & $49 \%$ & 1,214 & $42 \%$ \\
\hline Psoriatic Arthritis or Psoriasis & 19 & $13 \%$ & 582 & $20 \%$ \\
\hline Crohn's Disease & 6 & $4 \%$ & 191 & $7 \%$ \\
\hline Ulcerative Colitis & 8 & $5 \%$ & 157 & $5 \%$ \\
\hline \multicolumn{5}{|l|}{ Concomitant RA-Medications During Follow-Up Period } \\
\hline Methotrexate & 31 & $21 \%$ & 652 & $23 \%$ \\
\hline Sulfasalazine & 21 & $14 \%$ & 340 & $12 \%$ \\
\hline \multicolumn{5}{|l|}{ Dosing Characteristics } \\
\hline Average \# of doses within follow up period & 2.6 & 1.6 & 4.7 & 2.4 \\
\hline Mean \# of weeks between doses & 10.1 & 5.1 & 9.9 & 3.8 \\
\hline Mean \# of days between 1 st and $2^{\text {nas }}$ dose & 75 & 48 & 70 & 34 \\
\hline Mean $\#$ of days between 2 nd and $3 r d$ dose & 72 & 38 & 70 & 29 \\
\hline Mean \# of days between $3 r d$ and 4th dose & 65 & 31 & 67 & 26 \\
\hline Mean \# of vials per Infusion & 3.6 & 1.6 & 4.4 & 1.9 \\
\hline \multicolumn{5}{|l|}{ Switching } \\
\hline$\#$ and $\%$ of patients with 21 switch & 110 & $74 \%$ & 471 & $16 \%$ \\
\hline$\%$ of Primary Switches from CT-P13 to IFX & 103 & $94 \%$ & NA & NA \\
\hline \multicolumn{5}{|l|}{ Discontinuation } \\
\hline \# of Patients Confirmed to Have Discontinued & 121 & $82 \%$ & 1,089 & $38 \%$ \\
\hline Time to confirmed discontinuation (days) & 94 & 58 & 126 & 91 \\
\hline Time to any discontinuation or censoring (days): & 124 & 87 & 256 & 138 \\
\hline
\end{tabular}

Conclusions: This study shows switching from IFX to CT-P13 was infrequent. However, in those switching to CT-P13, a high percentage (82\%) of CT-P13 discontinuation was observed and the majority returned to IFX. Further studies are needed to understand the reasons for these observations.

Disclosure of Interest: Y. Yazici Grant/research support from: Janssen Scientific Affairs, LLC, L. Xie Consultant for: Janssen Scientific Affairs, LLC, A. Ogbomo Consultant for: Janssen Scientific Affairs, LLC, D. Parenti Employee of: Janssen Scientific Affairs, LLC, K. Goyal Employee of: Janssen Scientific Affairs, LLC, A. Teeple Employee of: Janssen Scientific Affairs, LLC, L. Ellis Employee of: Janssen Scientific Affairs, LLC, I. Simsek Grant/research support from: Janssen Scientific Affairs, LLC

DOI: 10.1136/annrheumdis-2017-eular.1128

\section{SATURDAY, 17 JUNE 2017}

Rheumatoid arthritis - other biologic treatment

\section{SAT0176 PATTERNS OF BIOLOGIC DMARD MONOTHERAPY IN A LARGE NATIONWIDE RHEUMATOID ARTHRITIS COHORT: DATA FROM 1036 PATIENTS}

K. Thomas ${ }^{1}$, E. Kaltsonoudis ${ }^{2}$, A. Drosos ${ }^{2}$, I. Papalopoulos ${ }^{3}$, P. Sidiropoulos ${ }^{3}$, P. Katsimbri ${ }^{1}$, D. Boumpas ${ }^{1}$, P. Tsatsani ${ }^{4}$, S. Gazi ${ }^{4}$, E.P. Grika ${ }^{1}$,

P.G. Vlachoyiannopoulos ${ }^{1}$, K. Fragiadaki ${ }^{1}$, M. Tektonidou ${ }^{1}$, P.P. Sfikakis ${ }^{1}$, K. Karagianni ${ }^{1}$, L.I. Sakkas ${ }^{5}$, L. Pantazi ${ }^{6}$, K. Boki ${ }^{6}$, T. Dimitroulas ${ }^{7}$,

A. Garyfallos ${ }^{7}$, D. Kasimos ${ }^{8}$, G. Evangelatos ${ }^{9}$, A. lliopoulos $^{9}$, C. Georganas ${ }^{10}$, P. Vounotrypidis ${ }^{10}$, M. Areti $^{10}$, P. Georgiou ${ }^{11}$, K. Delis $^{10}, \mathrm{~K}_{\text {. Mavragani }}{ }^{1}$, I. Bournazos ${ }^{10}$, G. Katsifis ${ }^{12}$, C. Mavromatis ${ }^{10}$, G.D. Kitas ${ }^{13}$, D. Vassilopoulos ${ }^{1}$ 